\title{
Double skin suitable for Mediterranean climate in school-gym buildings.
}

\author{
Margherita Finamore* \\ Public Works Department, Municipality of Pesaro - Pesaro, Italy
}

\begin{abstract}
The requalification of public buildings especially schools, represents an important task for the Italian Government not only for their educational function but also for the important social role they play. These schools were usually constructions built during the " 60 s or " 70 s with old technical characteristics and expensive maintenance costs which causes a serious waste of energy. Due to the large number of schools scattered nationwide and the limited space for new buildings, it is better to refurbish them using design choices that improve their architectural quality and structural and functional efficiency. This study focuses on the restoration and energy building improvement of a school-gym located in the seaside town of Pesaro, in the center of Italy. With careful design based on the analysis of the Mediterranean climate data of the site and the microclimate related to the precise position of the building, the design concept achieves high performance energy saving and lower production of $\mathrm{CO} 2$.
\end{abstract}

\section{Introduction}

Redevelopment could be an effective response to the urgent ecological, energy and economic crises if the energy efficiency of public buildings can be enhanced using renewable energy and innovative technologies with a low environmental impact.

For this reason, the Public Works Department of Pesaro Council is undertaking a structured set of projects addressing the issue of retrofit public buildings built in the second half of the 20th century to help in defining best practices for planning design and construction and developing Green Public Procurement as well.

The construction sector is showing signs that the building sector will be driven by the development of sustainable actions in building refurbishment, qualified planning and technological innovation.

These can also be seen as strategic, cultural and technical opportunity offering a way out of the economic and financial crisis which the building sector is suffering. In this scenario the measures required to ensure high quality building retrofitting can be related to the appropriate response not only to solve obsolete features but also reach new standards of comfort, security and usability.

Policy-makers should be responsible for introducing new rules to integrate the existing regulatory framework with innovative forms of incentives and simplified bureaucracy.

Retrofitting existing buildings to improve sustainability and energy performance would, on one hand, ensure a new image for cities and on the other stimulate the economy by the development of new entrepreneurship.

Improve sustainability could also attract investment to update public buildings using innovative and sustainable technologies and products. [1]

In order to define best practices, pilot projects such as this one can open up new operative perspectives, the
Public Works Department of Pesaro Council is currently focusing on retrofit technology for existing buildings.

Since buildings consume a significant amount of energy (40 percent of the nation's total energy consumption), particularly for heating and cooling (32 percent), and because existing buildings comprise the largest segment of the urban environment, it is important to start energy conservation retrofits to reduce energy consumption and the cost of heating, cooling, lighting and maintenance. In the building sector, most energy is consumed by existing buildings while the replacement rate of existing buildings by the new-build is only around $1.0-3.0 \%$ per annum [2].

But conserving energy is not the only reason for retrofitting existing buildings.

Another goal should be to create a high-performance building by applying the integrated, whole-building design process, from the planning phase to the construction until the end of life of the building itself.

In this way the buildings will be less costly to operate, will increase in value, last longer, and contribute to a better, healthier, and more comfortable environment for people in which to live and work.

Improving indoor environmental quality, decreasing moisture penetration, and reducing mold all will result in improved occupant health and productivity.

Further, when thinking on a retrofit, upgrading for accessibility, safety and security should be considered at the same time.

The school buildings retrofitting must be given special attention due to the educational value and because schools are strategic buildings in case of earthquake.

Energy efficiency is a main driver of the Italian Government actions [3] which focus not only on the control of the running costs, but moreover in enhance pupils' awareness on environmental problems, general wellbeing and learning performance through the accurate design and renovation of schools' spaces [4].

m.finamore@comune.pesaro.pu.it 
Planning major renovations and retrofits for existing buildings to include sustainability initiatives will also reduce operation costs and environmental impacts, and can increase building adaptability, durability, and resiliency.

\subsection{Energy performance at the National school building}

The attention to existing school buildings in Italy is increasing due to National strategies targeting at improve the conditions of the more than 42,000 schools composing the educational building stock which in the $35 \%$ of the cases are in need of maintenance and heavy refurbishment to achieve levels of environmental well-being, health, attractiveness and cost-effectiveness.

The $75 \%$ of Italian schools dated before energy laws and the distribution in the territory from north to south does not change. The $33 \%$ of the school buildings dates before $\mathrm{L}$. $373 / 76$ [5] and about the $50 \%$ has been realized after the law nonetheless, the energy quality did not improve dramatically. The $25 \%$ of the school building dates after ' 80 s and thus towards the L.10/91 [6]. Moreover, the progressive ageing of the schools means a crucial need of improvement and performance to accomplish current standards [7] and EU Directives [8]. The school building stock counts over 62,000 schools of which about 45,000 public, largely overtake the public housing sector with about 1 million TEP of energy consumption per year of which $70 \%$ of heating and $30 \%$ of electricity. The potential of reduction, with effects on energy, environment and social aspects is impressive. [9]

\subsection{The bioclimatic architecture}

The term bioclimatic (or sustainable) architecture refers to an alternative way of constructing buildings so that local climatic conditions are taken into account and a number of passive solar technologies are utilized in order to improve energy efficiency; the term passive solar technologies refers to heating or cooling techniques that passively absorb (or protect from, e.g. natural shading) the energy of the sun and have no plant components. Bioclimatic structures are built in such a way that, during winter months, exposure to cold temperatures is minimized and solar gains are maximized; during the summer, bioclimatic structures are shaded from the sun and various cooling techniques are employed, often with the aid of renewable energy sources. In addition, locally available building materials may be used. [14]

The renovation project takes into account a careful design based on sustainable bioclimatic study of the site, considering the external environment, Coastal Mediterranean climate, and the particular internal conditions: high water vapour production.

Thermal inertia is a fundamental parameter to improve comfort conditions and promote energy saving in buildings in mild and hot climates [9].

Therefore, it is important to study, analyse and implement bioclimatic architectural systems that contribute to the reduction of energy consumption while considering the possible retrofitting solutions offered at both passive and active levels.

\subsection{The exiting building project concept}

The design of the school-gym redevelopment arose from the awareness and respect for the original building shape and structure, which was then futuristic and now still has a contemporary design.

First of all, the project was based on conserving the original values. It was also relevant to study the technical characteristics and the thermal behavior of the building itself to understand how improve the envelope and discover that did not work at all.

The school "Dante Alighieri" is a large $4.200 \mathrm{mq}$ building divided into three main parts: the school, the biggest which consists of 4 floors; the gym and the auditorium.

The gym is between the school and the auditorium like a big box overhanging the school entrance hall. The first step was the historical investigation that was necessary to understand the conception and the significance of the building, the techniques and the skills used in its construction.

Table 1. School-gym building data.

\begin{tabular}{|l|l|}
\hline Total usable floor area & $634,56 \mathrm{mq}$ \\
\hline Heated gross volume & $4.597,84 \mathrm{mc}$ \\
\hline Dispersing gross surface & $1.598,15 \mathrm{mq}$ \\
\hline Volume/surface & 0.35 \\
\hline
\end{tabular}

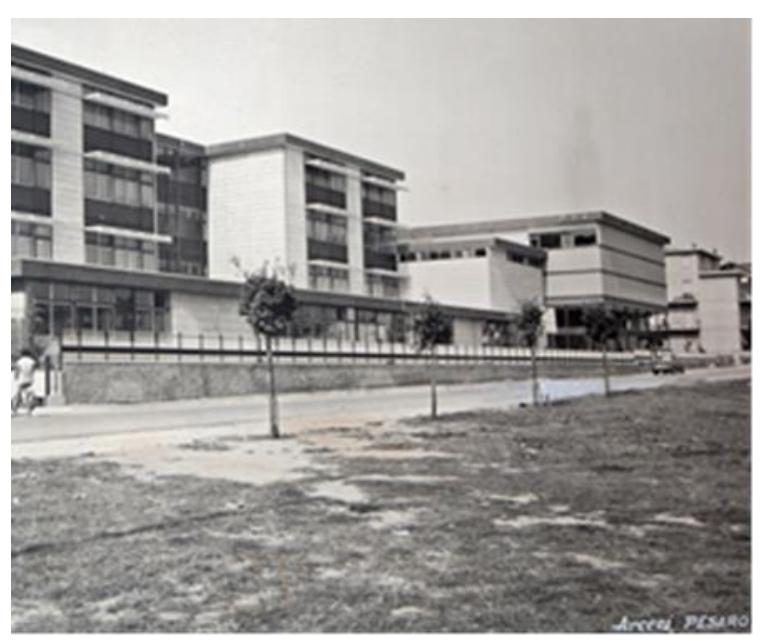

Fig. 1. The original school built in 1964 and before the work in 2000 


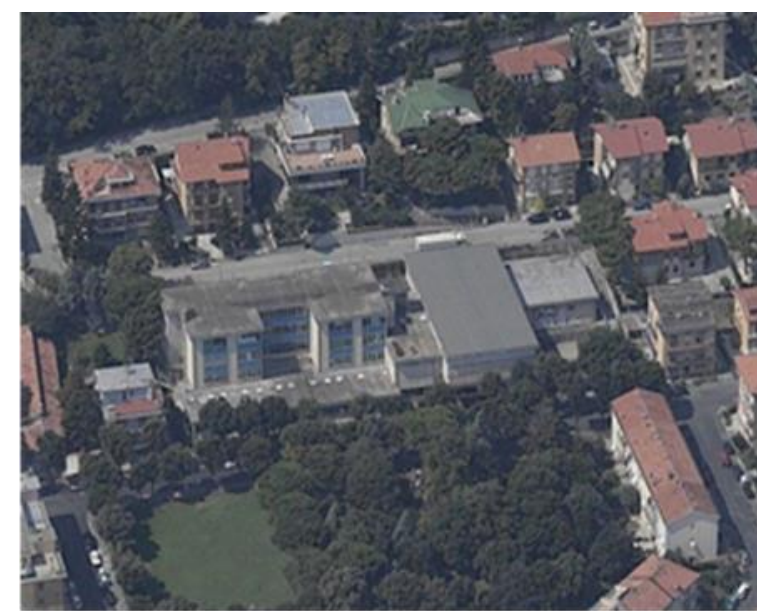

Fig. 2. The original school built in 1964 and before the work in 2000 .

The whole building, subject to a ministerial competition, was built in 1964 for 560 students using experimental dry assembly technology: the building is made of structural iron beams and pillars and heavy concrete-gypsum panels dry assembled for the building envelope.

This kind of technology is very often used but it has a lot of thermal dispersions due to the lack of insulation and the presence of thermal bridges causing a drop in the energy performance and the rise of consumption and a low level of hygro-thermal comfort. The whole building was very damaged cause of its age and the lack of maintenance, too. Therefore, the gym was closed for several years and the school had to pay the students transport for another gym.

In 2005 the first renovation project involved the restoration of the entire building, but financial resources made it possible only to carry out the project for the gym.

The Public Administration resources were very little, and it wasn't easy to work with them and respect the allocated budget.

In 2008 to make the building earthquake-proof a project provided only the structural and plant engineering renovation.

\section{Material and methods}

The works began on 27 December 2010 and they finished on March 2010. During the execution of the work, we realized the necessity of studying the behavior of the gym envelope to substitute the old building with an energy saving building but using the same dry assembly technology and respecting the assigned budget.

The solution was inspired by the old building itself: to replace the old concrete panels with a new envelope with different characteristics to obtain energy efficiency and up-to-date comfort quality.

The renovation of the gym represented the opportunity modernize and achieve a new design with a sustainable development approach.

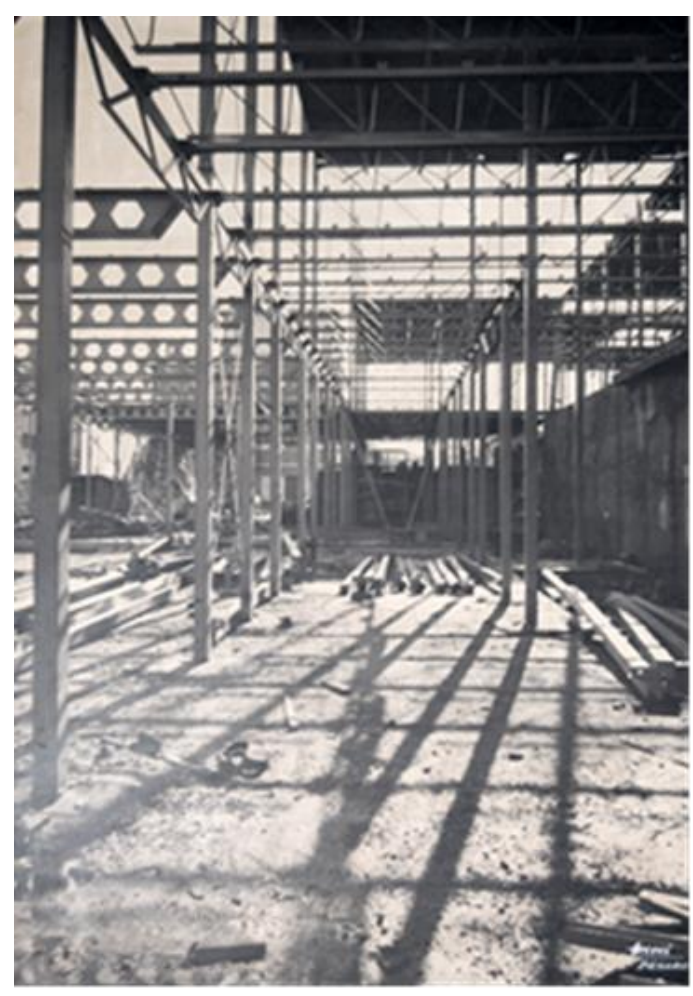

Fig. 3. The original structure in 1964.

The more the envelope is energy saving, the more the system engineering plants would be easier to manage, less expensive and with cheaper maintenance. The aim of the design concept was to create a new high saving energy envelope with an easier technique to refurbish public buildings in general.

The new project started with a careful study of the climatic data and the specific microclimate: orientation, proximity of hills, rain rate, temperature, damp, speed and direction of the dominant winds, summer sea breezes, to protect the building from heat and cold at the same time. The seaside town of Pesaro is located at $43^{\circ}$ North with very cold winters and hot summers with a lot of all year-round humidity. All these data were very important to project a high energy saving building envelope and ensure the right hygrometric balance and comfort for the occupants, because without this analytical analysis of the microclimate the performance of the envelope risked being only theoretical and not truly effective. These context data influence not only the project but, which is more important, the result of the project itself.

Due to Mediterranean climate, it is very relevant to estimate the energy demand and to have a highly efficient envelope in winter and in summer as well and collect these kinds of data as much as possible.

The Mediterranean climate distinguishes for a mild heating season and a hot and usually very dump cooling season. All along the year solar radiation is plentiful and the daily range of temperature during the summer is large, due to clear conditions. This environment allowed to design and build a low energy concept building on the basis of passive heating and cooling technologies, 
supported, when required, by short time active conditioning.

The study focused on taking maximum advantage of the free thermal loads of the outside air, free clean and renewable energy from the sun for heating, summer sea breezes for cooling, and intended to make the building envelope take on an "active" role in energy saving.

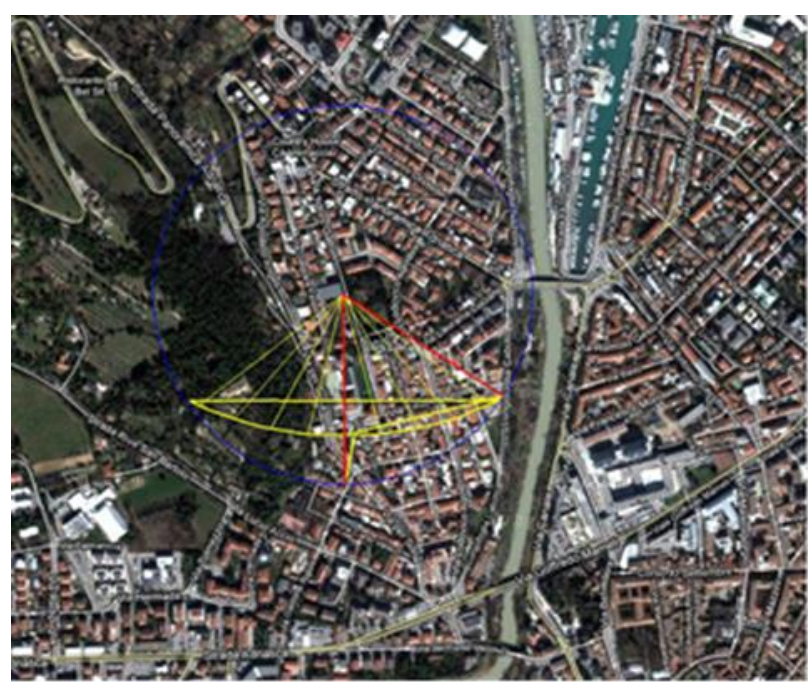

Fig. 4. Analysis of microclimate.

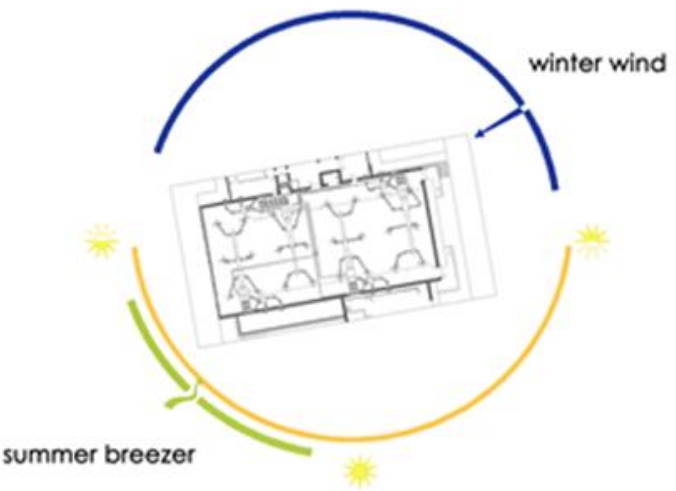

CLIMATIC CONTROL

energy saving by natural isolation

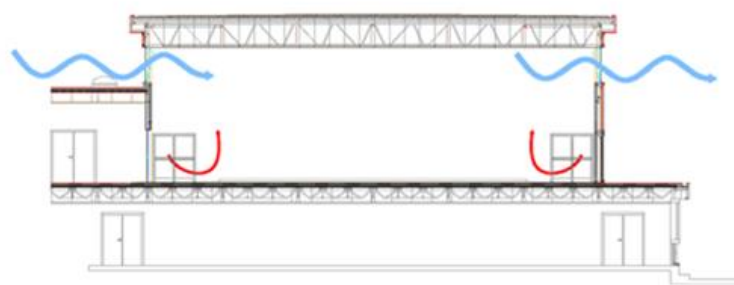

Fig. 5. Plant engineering ventilation control with the aid of the existing windows.

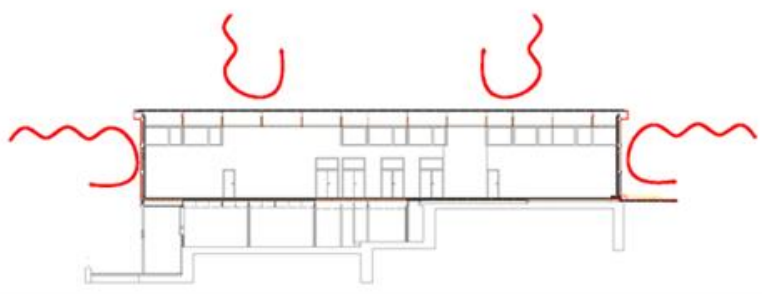

Fig. 6. Summer heat control.

The main difficulty was to achieve different kind of goals at the same time, because public buildings must satisfy a lot of mandatory specifications and sports buildings have much more variables such as high noise control, dissipation of moisture generated by sport and wall resistance to damage.

All the goals that the project tried to answer were:

- energy efficiency;

- earthquake and fire resistance;

- dissipation of moisture generated by sport;

- noise control;

- indoor comfort;

- minimizing the need for maintenance;

- use of eco-materials considering the lifecycle of the materials of the whole building;

- contemporary design for the texture panels;

- run a construction site in a sustainable way.

The most efficient solution, [10] where all the goals were met, was a high-performance envelope made of a suitable sequence of layers using a dry, clean and fast construction method with eco-materials: fiber cement panels, thinner and lighter than the demolished ones, creating greater seismic safety, painted and treated for the outdoors and suitable densities for noise control; strongly ventilated air space; insulation with rock-wool of different densities; fire panels; steam barrier for damp control.

A strong insulated envelope with little thermal losses is achieved by minimizing the environmental impact with the control of natural ventilation and daylight.

\section{Results and Discussion}

\subsection{Energy consumption values and possibilities for the energy saving in the renovation design.}

The envelope so studied enables the elimination of the heat bridges to minimize energy consumption for heat in winter and avoid overheating in summer.

This envelope with an external ventilated façade allows at the same time to reduce consumption for cooling. Thanks to the high value of the 12-hour thermal phase shift and the use of the high density natural and organic materials optimum temperature values are reached in summer which reduces the use of airconditioners. 
The interior envelope was insulated with wood wool mineralised with magnesite panels. All components of the panels are made of natural materials with a total absence of harmful substances. This, therefore, makes the panels particularly suitable for a school and for the well-being of students and teachers. These panels provide thermal as well as acoustic insulation. The panels also have another advantage in that there are no requirements for special maintenance, they are resistance to compression, and are vapour permeable and flame resistant.

The new envelope reaches, in relation to the previous situation, the following thermal transmittance values:

Table 2. Before and after thermal transmittance values

\begin{tabular}{|c|c|c|c|}
\hline & $\begin{array}{c}\mathrm{U} \text { value } \\
\text { (before } \\
\text { renovation) } \\
\mathrm{W} / \mathrm{m} 2 .^{\circ} \mathrm{K}\end{array}$ & $\begin{array}{c}\mathrm{U} \text { value } \\
\text { (after } \\
\text { renovation) } \\
\mathrm{W} / \mathrm{m} 2 .^{\circ} \mathrm{K}\end{array}$ & Difference \\
\hline $\begin{array}{c}\text { Opaque } \\
\text { element }\end{array}$ & 1.747 & 0.163 & $-90 \%$ \\
\hline $\begin{array}{c}\text { Transparent } \\
\text { element }\end{array}$ & 2.8 & 1.8 & $-35 \%$ \\
\hline External attic & 1.103 & 0.277 & $-74 \%$ \\
\hline $\begin{array}{c}\text { Attic of } \\
\text { coverage }\end{array}$ & 2.112 & 0.312 & $-85 \%$ \\
\hline
\end{tabular}

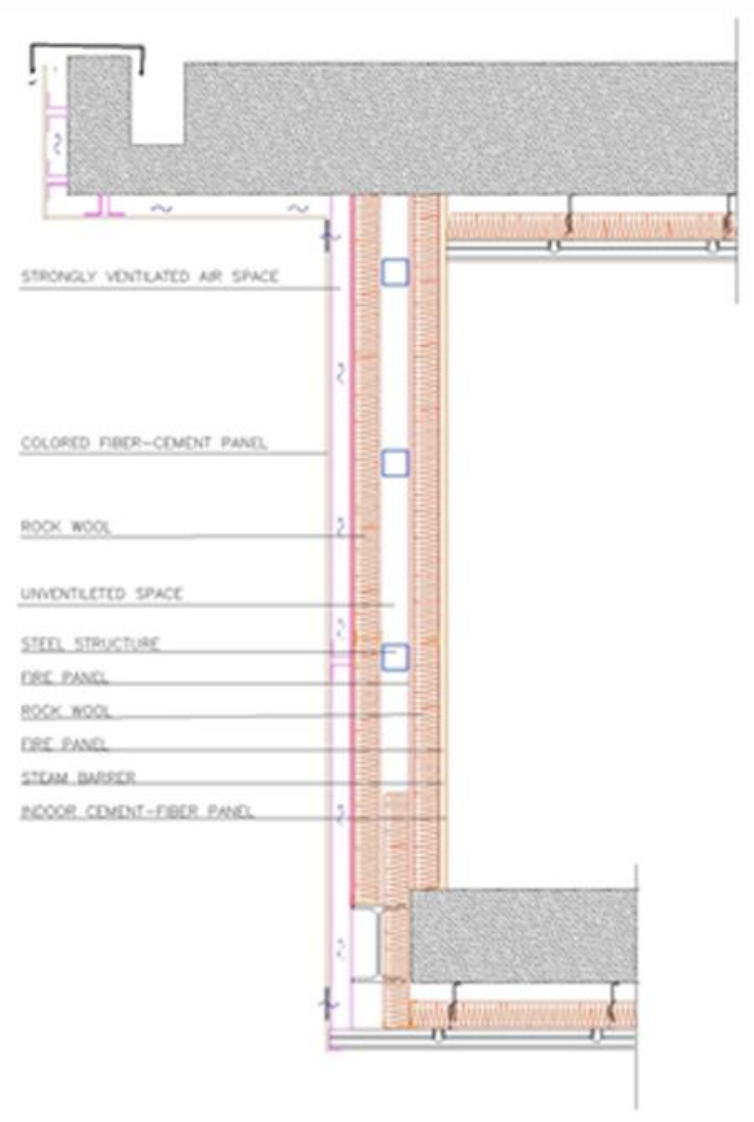

Fig. 7. The new envelope.
The energy building performance was calculated using the dynamic simulation of the building. [11] This method provided data of heat losses, energy requirements and consumptions and allowed to choose the best solution for reaching high performance minimizing the construction costs [12] [13].

A new independent heat generation plant was installed only for the gym to monitor the consumption, applying a variable refrigerant gas electric heat pump.

The air conditioning system is made up of an external refrigerator unit located on the roof and 4 internal heat recovery units located within the gym's false ceiling.

The warm air produced is distributed inside the gym by ductwork with high induction anemostats diffusers. The exhaust air is expelled by means of the return environmental air grids flush to the floor located on the two longer parallel walls. The internal air is recycled at $3.000 \mathrm{mc} / \mathrm{h}$, by four heat recuperators which recover $50 \%$ of the heat. They are positioned in the ceiling and are connected both to the internal and external air systems to provide both return environmental clean air from outside and the expulsion of the unwanted air in the closed environment. The result of the envelope behaviour was controlled by a specific engineering calculation thermal programme: we analysed three thermal bridges between the wall and window, the wall and the false ceiling, the wall and the external floor to control fluxes of heat and to be sure that there weren't any constructional defects.

We also checked the envelope's thermal behaviour with a thermal camera to control the position of the insulation in the external walls and in the false ceiling.

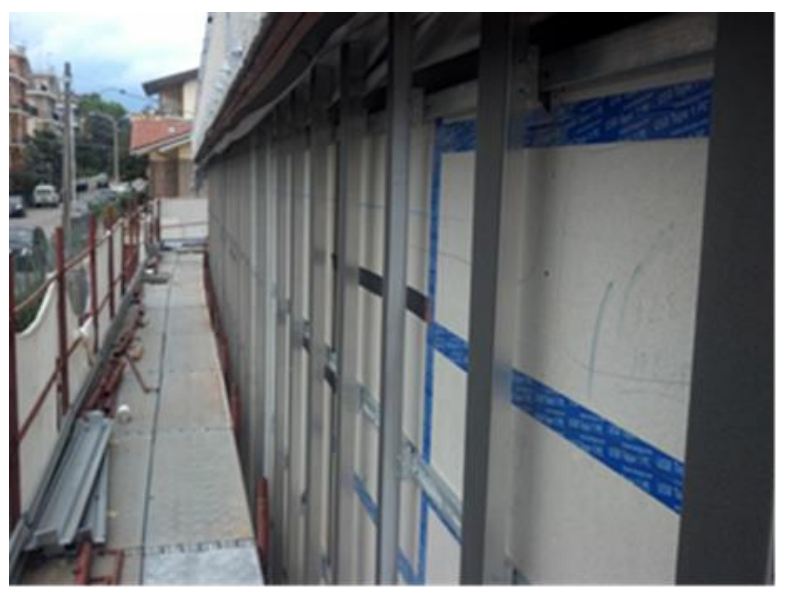

Fig. 8. Ventilated wall structure.

The exterior envelope of the building was covered by a fibre cement panel making a strong weather-proof cladding board characterised by its muted, matt finish. The material is highly resistant towards water staining and dirt and ensures a long-lasting and durable façade.

The design process was optimized by extensive energy simulations, resulting in an optimal energy balance and favorable thermal comfort conditions along the year. The building is instrumented with an accurate building automation control system to optimize the energy consumption. 
The Council Public Works Department has already refurbished the school auditorium using the same dry system technology as the gym envelope.

\section{Energy consumption results}

The renovation has achieved an $80 \%$ reduction of the primary energy need ( 117 to $22 \mathrm{kWh} / \mathrm{m} 2$.year). -primary energy need before renovation:

$117.00 \mathrm{kWh} / \mathrm{m} 2$.year

-primary energy need: $22.00 \mathrm{kWh} / \mathrm{m} 2$.year

-primary energy need for standard building:

$88 \mathrm{kWh} / \mathrm{m} 2$.year

Calculation method: UNITS 11300

\section{Renovation costs}

Renewable energy system cost: $341,202.00 €$

Total renovation cost: $721,533.00 €$

Cost $/ \mathrm{m} 2: 1,138 € / \mathrm{m} 2$

Cost/Pupil: 1,288 €/pupil

Related to the present consumption costs the pay-back period of $€$. 341,202.00 required 25 years. According with the energy performance reached after works we can estimate $€$. 13,205.00 energy saving costs per year.

It is difficult in this case compare the monitoring data because we know the consumption of the whole school, but we don't know the specific consumption costs of the school-gym in the past. The retrofitting works made the school-gym plant independent from the school building and the auditorium and doing so the use of the gym is optimized.

\subsection{Environmentally Sustainable Approach.}

The project also provides for the installation of photovoltaic panels for electricity and solar panels for hot water to make the building economical and functional not only for the students but also the adults who use the gym when the school is closed without heating the whole school.

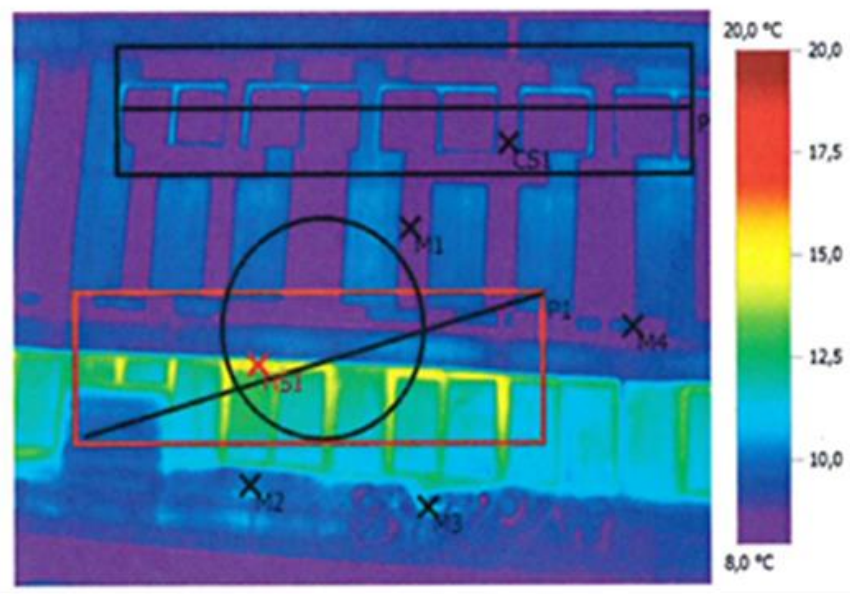

Fig. 9. The North thermal behaviour façade controlled with the thermo-camera
The aim of sustainable design concept for existing buildings is to make them energy efficient by climate change mitigation and reduce the severe impact on health.

Public Administrations should pay a lot of attention to school buildings because children are more vulnerable health wise than adults.

Therefore, it is relevant to eliminate the environmental impact of building and create a capacity to build intelligent public buildings which are easy to use and an example for private buildings.

This project tried to find a green solution and tried to create a sustainable system of building refurbishment. It was a "green challenge" to find an efficient solution with a dry technical system easy to install and easy to use.

The design concept used the method of dry construction which meets the criteria of sustainability and in addition the efforts expended on research and use of natural materials to create a healthy environment in which to live, have permitted a fast construction and clean site.

The project could be applied to the whole of Europe with particular effectiveness in the Mediterranean area because the materials of the envelope can be chosen in order to have characteristics suitable to specific microclimate. Instead of external fiber cement panels, brick panels or even ceramic panels may be used according to the type of building to be recovered.

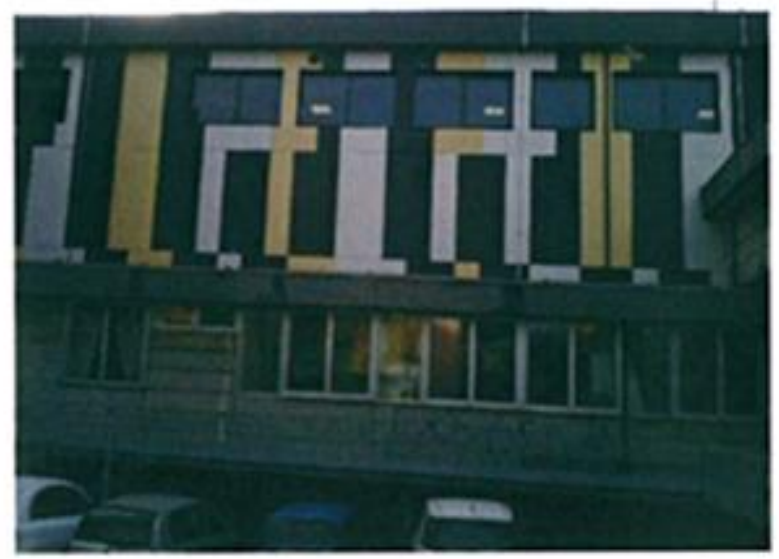




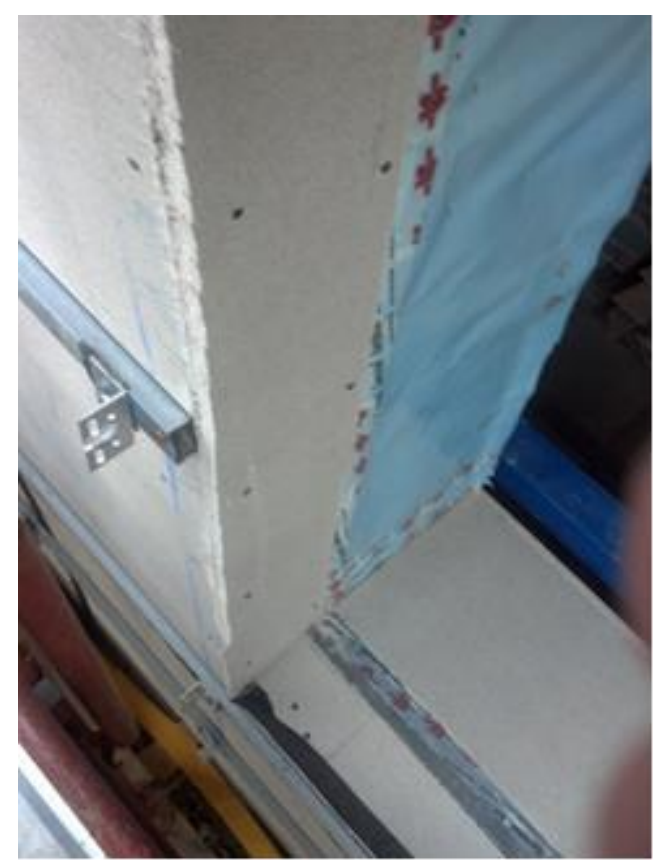

Fig. 10. Window detail.

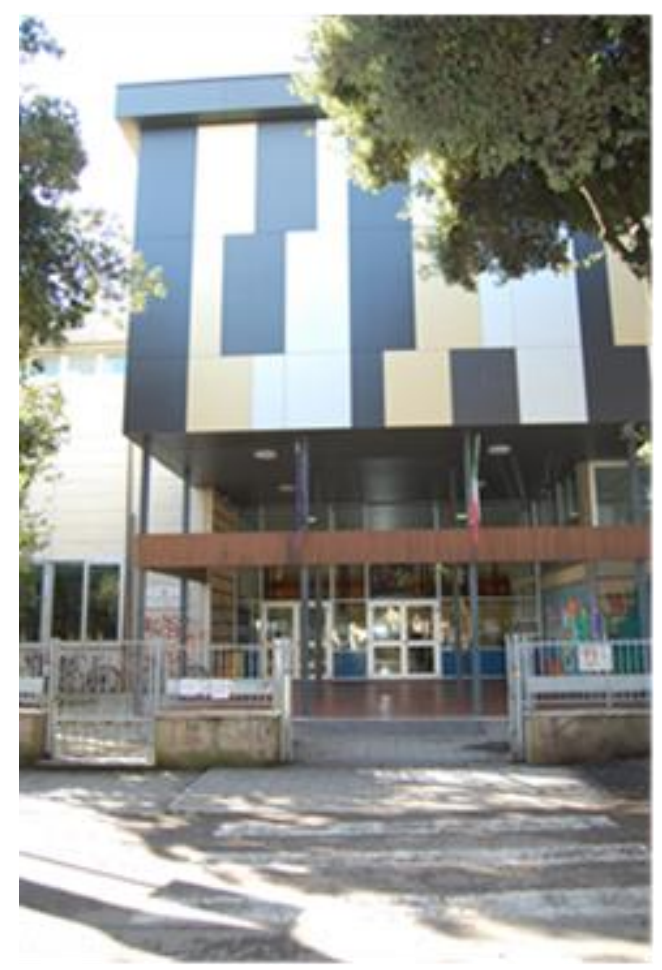

Fig. 12. The main entrance.

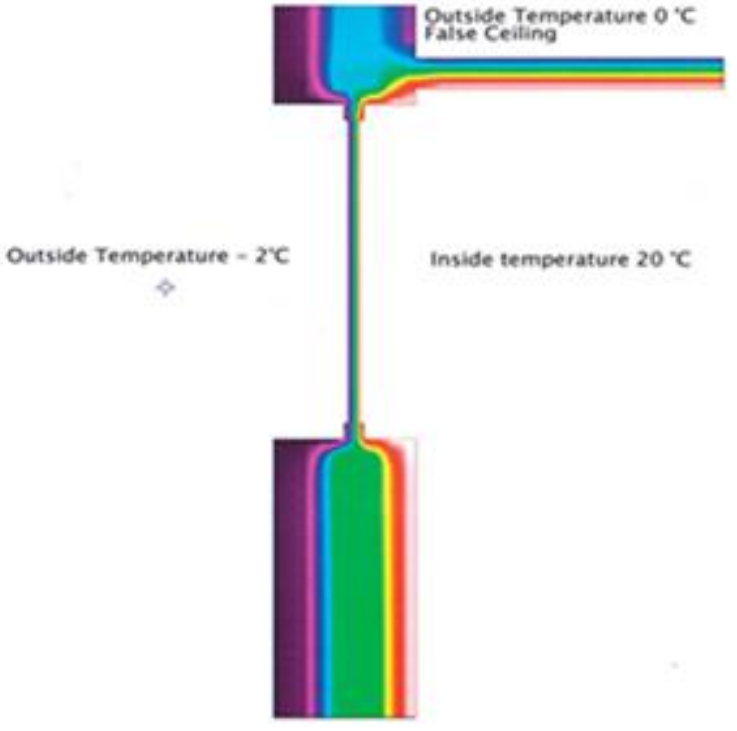

Fig. 11. Thermal bridges control.

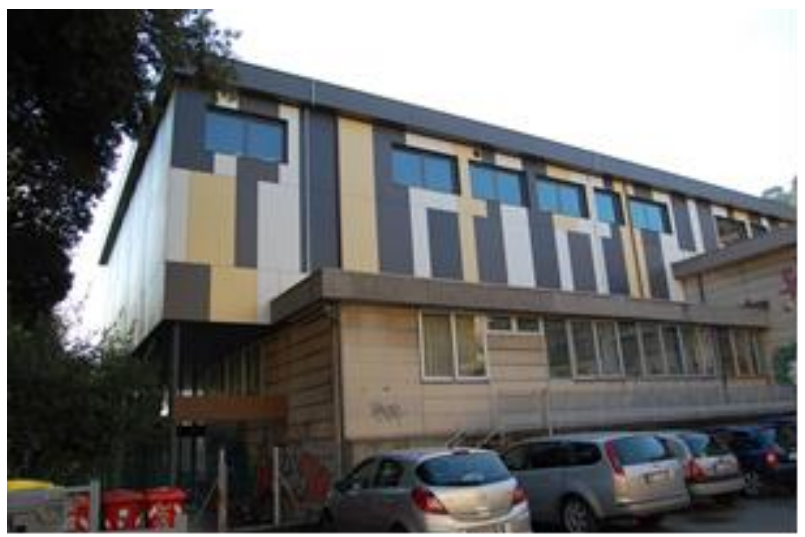

Fig. 13. North façade. 
Table 3. Values obtained after works

\begin{tabular}{|l|r|}
\hline indicator & present values measured \\
\hline Annual primary energy requirement & $14.018,00 \mathrm{Kwh} /$ year \\
\hline Consumption of electricity & $6.448,00 \mathrm{Kwh} /$ year \\
\hline Annual thermal energy requirement & $26.619,00 \mathrm{Kwh} /$ year \\
\hline Share of renewable energy of the Legislative Decree 28 03/03/2011 Annex 3 - paragraph 8 & $15.884,00 \mathrm{Kwh} /$ year \\
\hline Seasonal performance factor of heat pump SBF & 3,76 \\
\hline Overall energy performance (EPG) & $3,05 \mathrm{Kwh} / \mathrm{mc}$ year \\
\hline Energy class & $\mathrm{A}+$ \\
\hline Kwh of energy saved & $60.667,57$ \\
\hline Kwh renewable heat produced & $15.880,28$ \\
\hline CO2 emissions avoided & $12.272,69 \mathrm{Kg} \mathrm{CO} / \mathrm{a}$ \\
\hline
\end{tabular}

\section{Conclusion}

This retrofit lays the foundation for the development of sustainability criteria for the school (e.g. environmental integrity and economic efficiency) as the retrofit is done on the existing structure of steel, using a lighter external cladding as a "ventilated wall", new insulation for the false ceiling and new glass frames, with a preference of materials from a natural origin. The building envelope acts as a "ventilated wall" - the building skin interacts with the internal and external environment by taking into account the daily temperature and season.

This project demonstrates how public buildings can be renovated without being destroyed, obtain an excellent energy efficiency result and create a sustainable environment. Even if the project was developed in 2010 the values of energy efficiency reach are very close to a nearly Zero Energy Building [16].

This new dry system assembly can be duplicated and adapted without losing efficiency and also demonstrate that the envelope with strong insulation isn't so expensive.

These results are also due to a mechanism installed on the heat pump that measures the heat supplied to the environment while an electric meter measures the electricity absorption of the heat pump.

From the ratio of the two quantities: supplied heat/absorbed heat the seasonal performance factor of the heat pump is calculated so we can monitor the energy savings and the real annual consumption of the building.

We also can monitor the energy savings and the real annual consumption of the building. If we consider that the recently renovated building is a small part of the entire school, the result is remarkable. If the whole school were renovated in this way these would be $75 \%$ saving.

The type of construction studied can be applied and replicated also to all new buildings and above of existing ones whose structures are made of beams and columns.

Naturally the supporting structure can be formed of concrete as well or iron as in this case because the structure does not affect the thermal behavior of the building if the envelope is energy saving.
In fact, the envelope is independent and meets simultaneously the criteria for energy saving, acoustic comfort and fire safety.

The use of organic materials allows also a clean construction site and reduce $\mathrm{CO} 2$ emissions and waste.

The school-gym refurbishment allowed us to test a lot of positive elements like:

- ease construction,

- high parameters of energy savings,

- speed of execution,

- ease of adapting to other existing buildings that need to be renovated,

- the possibility of using different thicknesses and densities materials which can achieve good results in any European climate,

- ease in replicating this construction by placing the outside panels with different finishing elements such as ceramic or terracotta.

These elements could attract others and lead to a new approach towards respect of the environmental and promote sustainable system building refurbishment that is based on the analysis of the micro-climate and the existing building itself.

This project tried also to demonstrate a sustainable system for buildings renovation with the essential contribution of the dynamic thermal simulation.

The design concept experimented a dry construction method that makes the building be flexible and functional as a material banks: the building envelope is designed with a dry assembly construction process that can be reverse, so the envelope materials can be dismantled and reuse in another building.

The natural materials used for the insulation have good thermal resistance thanks to it the school-gym is become an energy efficient building that requires only 35 $\mathrm{kwh} / \mathrm{m} 2$ per year for heating and therefore it is become less expensive in the consumption.

The use of the natural materials creates a healthy environment in which to live and also permitted a fast construction and a clean site to reduce $\mathrm{CO} 2$ emissions.

Thanks to the microclimate analysis the envelope takes an active role in the energy saving and the more the envelope is energy efficient, the more the system 
engineering plants are easier to manage, less expensive and with cheaper maintenance.

We can conclude that bioclimatic architecture approach that has adopted in this specific project could be exported to other areas with similar climates because it was proven to be good functional design strategies that resulted in large energy saving measures (each in its corresponding climate) related to solar protection, humidification or temperature increases.

Understanding why it is important to retrofit existing buildings will kick off the community's effort to move towards a green society [17]. The retrofitting of existing buildings is a realistic, economically smart, and feasible way to enhance buildings not only aesthetically, but for one's health, as the smallest retrofitting changes reap big results. Simple changes done by retrofitting will inevitably have a positive impact on more than one thing, and the most important impact is one's improvement in health of body and mind.

A truly sustainable building is not just one that incorporates energy efficient technology and fulfils the standards of given energy certificates, but also takes into account the effects on the social and physical wellbeing of its users and the climate change [15].

\section{Acknowledgments}

Special thanks to Valentina Radi PhD in Technology of Architecture - Contract Professor at the University of Architecture in Ferrara, Italy, for publishing in UT 12/2014 Riqualificazione architettonica ed energetica Palestra della scuola media D.Alighieri, Pesaro.

Special thanks to Josep Mayos, of CIMNE, el Centre Internacional de Mètodes Numèrics en Enginyeria and responsible of selecting buildings for publishing in the prestigious BUILDUP website, the European portal for energy efficiency in buildings of the European Commission for having selected the project as a "Highlighted Case of August 2017".

http://www.buildup.eu/en/practices/cases/dantealighieri-middle-school-renovation-gymnasium-pesaroitaly

The project was selected to be presented at the Advanced Building Skin Conference 2017 in Bern

http://www.bitcongress.com/wcsm2018/

And at the BIT's $4^{\text {th }}$ Annual World Congress of Smart Materials 2018 in Osaka

http://www.bitcongress.com/wcsm2018/

\section{References}

1. Mariangela Bellomo, Sergio Pone, Il retrofit tecnologico degli edifici esistenti: qualità dell'abitare, sostenibilità ambientale, rilancio economico, Techne 01/2011; 82-87.

2. Zhenjun Ma, Paul Cooper, Daniel Daly, Laia Ledo, Existing Building Retrofits: Methodology and State-of-the-Art, Energy and Buildings 2012; 55(12):889-902.
3. ENEA, Guida all'efficienza energetica negli edifici scolastici, Presidenza del Consiglio dei Ministri, Struttura di Missione per l'Edilizia

Scolastica, Ministero dell'Ambiente, della tutela del territorio e del mare, MIUR, 2016.

4. Ministero dell'Istruzione, dell'Università e della Ricerca MIUR. Linee Guida per le architetture interne delle scuole, 11 Aprile 2013.

5. Legge ordinaria del Parlamento $n^{\circ} 373 / 76$ Norme per il contenimento del consumo energetico per usi termici negli edifici. pubblicata sulla Gazzetta Ufficiale Italiana $\mathrm{n}^{\circ} 148$ del 07/06/1976.

6. Legge 9 gennaio 1991, n. 10 , in materia di Norme per l'attuazione del Piano energetico nazionale in materia di uso razionale dell'energia, di risparmio energetico e di sviluppo delle fonti rinnovabili di energia.

7. B. Basarir, B.S. Diri, C. Diri. Energy efficient retrofit methods at the building envelopes of the school buildings. 2012.

8. Directive 2010/31/EU of The European Parliament and of the Council of 19 May 2010 on the energy performance of buildings (recast), Official Journal of the European Union, 18.6.2010, L 153/13.

9. Enrico De Angelisa, Lavinia C. Tagliabue, Fulvio Re Cecconia, Andrea G. Mainini, A simple method for the comparison of bioclimatic design strategies based on dynamic indoor thermal comfort assessment for school buildings, Procedia Engineering 180 (2017) $870-880$.

10. Decreto Ministeriale 18/12/1975, Norme tecniche aggiornate relative all'edilizia scolastica, ivi compresi gli indici di funzionalità didattica, edilizia ed urbanistica da osservarsi nell'esecuzione di opere di edilizia scolastica.

11. Norma UNI 10339 - Impianti di climatizzazione

12. Norma EN 13779 - Ventilazione per ambienti non residenziali - prestazioni richieste per i sistemi di ventilazione e condizionamento dei locali.

13. Decreto Legislativo n. 195 del 2005, Contenimento dei consumi energetici.

14. A.F. Tzikopoulos, M.C. Karatza, J.A. Paravantis, Modeling energy efficiency of bioclimatic buildings, Energy and Buildings 35 (2005) 529544

15. Kasper Guldager Jensen, Building a Circular Future, Danish Environmental Protection Agency - 2016

16. https://ec.europa.eu/energy/en/topics/energyefficiency/buildings/nearly-zero-energy-buildings

17. https://ec.europa.eu/energy/intelligent/projects/en/p rojects/zebra2020 